\title{
VACCINATION RATES FOR SYRIAN POPULATION UNDER TEMPORARY PROTECTION IN TURKEY
}

\author{
Dilek Öztaş ${ }^{1}$, Burak Kurt ${ }^{2}$, Muhsin Akbaba $^{3}$, Mesut Akyol ${ }^{4}$, Salih Mollahaliloğlu', Osman Topaç ${ }^{5}$ \\ 'Department of Public Health, Medical School, Ankara Yildirim Beyazit University, Ankara, Turkey \\ ${ }^{2}$ Central Community Health Centre, Kastamonu, Turkey \\ ${ }^{3}$ Department of Public Health, Medical School, Cukurova University, Adana, Turkey \\ ${ }^{4}$ Department of Biostatistics and Medical Informatics, Medical School, Ankara Yildirim Beyazit University, Ankara, Turkey \\ ${ }^{5}$ Directorate General of Public Health, Ministry of Health, Ankara, Turkey
}

\section{SUMMARY}

Objectives: The aim of this study was to gather information on demographic and health indicators, primarily vaccination status, of Syrians under temporary protection in five provinces of Turkey and to develop infrastructure for vaccination planning.

Methods: The population under study consists of 89,986 Syrian children, 0-4 years of age, residing in Ankara, Mersin, Gaziantep, Izmir, and Bursa. Initially, we planned to evaluate 2,339 children, although a total of 2,827 children were evaluated by the end of the study.

Results: Of these children, $74 \%$ were born in Turkey, while $20 \%$ were born in Syria. In addition, $22.4 \%(n=634)$ of the children were never vaccinated, and of these, $67.0 \%(n=425)$ were born in Turkey. In other words, one in five Syrian children born in Turkey $(20.3 \%)$ had never been vaccinated. Of the Syrian children under temporary protection, the missing vaccinations were as follows: hepatitis B (54.7\%); Bacillus CalmetteGuérin (62.5\%); five-component combined vaccine (64.6\%); conjugated pneumococcal vaccine $(58.0 \%)$; oral polio vaccine (70.8\%); measles, mumps, and rubella (76.6\%); varicella (66.8\%); and hepatitis A vaccine $(76.0 \%)$.

Conclusion: It is important to increase the immunization rates of Syrian children under temporary protection and establish regular vaccination procedures.

Key words: Syrian, refugee, vaccination status, Turkey

Address for correspondence: B. Kurt, Central Community Health Centre, Hepkebirler mah. Cumhuriyet cad. 64, 37100 Kastamonu, Turkey. E-mail: kurtburak@msn.com

https://doi.org/10.21101/cejph.a5543

\section{INTRODUCTION}

The war in Syria is in its seventh year, as of 2017, and is responsible for an increase in displaced persons at a global level. One out of every five people displaced worldwide is a Syrian citizen. Syria has now surpassed Afghanistan, which had ranked first in the world for 10 years, for numbers of temporarily protected persons as of 2014 (1). Turkey, which is facing an intensive influx of asylum seekers from Syria, has witnessed many migrations throughout history due to its geographical location and hosts the largest number of Syrian refugees. According to the United Nations High Commissioner for Refugees (UNHCR) data as of March 2018, there are 3,554,000 Syrians in Turkey. Approximately half of the population (45.9\%) is composed of women, while $13.4 \%$ are children $0-4$ years of age (2).

The war in Syria also increases health problems. It is of utmost importance that all children should be immunized before encountering infections to decrease the morbidity and mortality caused by active infections. Unvaccinated children contribute to the circulation and spread of infectious agents in a population and are a source of epidemics that can develop during preschool and school years. The primary purpose of immunization services is to prevent the emergence of vaccine-preventable disease, especially in infants and children, and prevent the deaths and disabilities resulting from these diseases. The primary goal is to leave no child unvaccinated (3).

People coming from different countries have very different disease burden. Because most of the countries where they come from are affected by war, primary healthcare services are hampered and vaccination cannot be administered regularly. Turkey is currently at risk of polio outbreaks due to immigration. The uncertainty of refugees' vaccination status, and them being unvaccinated or incompletely vaccinated, may cause an increase in incidence of vaccine-preventable diseases. Currently, there are refugees from regions endemic for meningitis, polio, and measles (4).

The World Health Organization (WHO) confirmed that cases of infantile paralysis were seen in Syria on October 29, 2013. The total number of cases in Syria was 35 as of January 21, 2014. Iraq experienced two such cases as of April 7, 2014. No new cases have been observed since these dates (1).

Within the last 2 years, measles has been observed in Turkey, concomitant with its increase throughout the world. In 2015, 68 foreign nationals, 64 Syrians, 3 Iraqis, and 1 Kazakhstani, had 
measles out of the 342 cases. In 2016, of the nine cases identified, eight were Syrian and one was Turkoman (5).

The immunization programme at border crossings consists of giving the following vaccines: oral polio vaccine (OPV) 0-15 years of age; measles, mumps, and rubella (MMR) 9 months-15 years; diphtheria, acellular pertussis, tetanus, inactivated polio, and Haemophilus influenzae type B - five-component combined vaccine (DaPT-IPV-Hib) less than 7 years of age; diphtheria, acellular pertussis, tetanus, and inactivated polio - four-component combined vaccine (DaPT-IPV) 7-12 years; and diphtheria-tetanus vaccine (Td) women between the ages of 15 and 49 (5). Under the Expanded Programme on Immunization (EPI), all vaccines administered during childhood and adulthood according to our national immunization schedule are also administered to the guest population under temporary protection in Turkey. Routine vaccination services are offered to infants $0-11$ months of age, women 15-49 years of age, and school-age children. In addition, OPV and measles vaccines are administered to the $0-15$-year age group within the scope of the campaign. Children under the age of 5 years have been vaccinated in regions where people have come from countries that are at risk of infantile paralysis. Currently, OPV is administered to all people at border crossings. As part of controlling the measles outbreak, immunizations were carried out on susceptible and unvaccinated migrant children (5).

Vaccinations for immigrant children aged 0-59 months were conducted on February 15 to March 3, 2017; May 3-8, 2017; and November 1-17, 2017. This programme predominantly concentrated on provinces with 25,000 or more Syrians and where they constituted $5 \%$ or more of the local population. These provinces included Adana, Adiyaman, Ankara, Bursa, Diyarbakir, Batman, Gaziantep, Hatay, Istanbul, Izmir, Kahramanmaras, Kayseri, Kilis, Kocaeli, Konya, Malatya, Mardin, Mersin, Osmaniye, and Sanliurfa. In addition, all immigrant children in the 0-59-month age group were screened in the remaining 61 provinces. All children who were unvaccinated received MMR vaccine, five-component combined vaccine, and hepatitis B vaccine (5).

\section{Research Scope}

This study aimed to gather information about demographic and health indicators, primarily vaccination status, from Syrian refugees who are the vast majority of people under temporary protection in five provinces of Turkey. The long-term objectives of the work are to build infrastructure for planning vaccination programmes to prevent disease, disability, and death and to improve the quality of provided services.

\section{MATERIALS AND METHODS}

\section{Study Population}

Children under 60 months of age were investigated in five provinces of Turkey with the greatest numbers of Syrian population. The sampling design was a weighted, multistage, stratified sampling approach. Provinces and districts were designated as strata. A total of 89,986 Syrian children, aged $0-4$ years, resided in the provinces of Ankara, Mersin, Gaziantep, Izmir, and Bursa. Information on demographic and health indicators, primarily vaccination status, were gathered from this temporarily protected population.

Because there was no prior information about the vaccination rate of Syrian children, aged 0-4 years, under temporary protection, the vaccination rate was presumed to be $50 \%$. The minimum number of children to be studied was calculated to be 2,339 out of a total of 89,986 , with a $95 \%$ confidence interval and an error margin of $2 \%$. The number of children to be studied was determined by the proportion of Syrian children in the 0-4-year age group compared to the total number of children aged $0-4$ years living in those provinces. The goal of enrolling at least 2,339 Syrian children aged $0-4$ years was realized as 2,827 children were enrolled at the completion of the study (Table 1).

\section{Data Collection}

A questionnaire was specifically developed for this study. The survey was prepared with the guidance and contribution of a specialized working team from the Ministry of Health, World Health Organization, and Yildirim Beyazit University. The Social and Humanities Ethics Committee of Ankara Yildirim Beyazit University approved the study.

Data collection occurred between January 24 and February 6, 2017. During this time period, project coordinators visited the target provinces and conducted quality control of the data collection. Each survey form was downloaded to the computer by two different people at two different times.

\section{Statistical Evaluation}

All data collected in the study were transferred to computer and checked for errors. Number (n) and percentage (\%) were used to represent descriptive statistics. MS Excel 2010 and IBM SPSS Statistics Version 22.0 IBM SPSS Statistics (IBM Corp. released 2013 IBM SPSS Statistics for Windows, Version 22.0,

Table 1. Planned and obtained sample size $(N=2,827)$

\begin{tabular}{|l|c|c|c|c|}
\hline Provinces & $\begin{array}{c}\text { Number of children aged } \\
\mathbf{0}-\mathbf{4} \text { years }\end{array}$ & Planned sample size & Actual sample size & Actual percentage \\
\hline Ankara & 8,760 & 228 & 292 & 128.1 \\
\hline Mersin & 18,715 & 486 & 613 & 126.1 \\
\hline Gaziantep & 43,179 & 1,122 & 1,304 & 116.2 \\
\hline Izmir & 14,809 & 385 & 478 & 124.2 \\
\hline Bursa & 4,523 & 118 & 140 & 118.6 \\
\hline Total & 89,986 & 2,339 & 2,827 & 120.9 \\
\hline
\end{tabular}


Armonk, NY: IBM Corp.) programs were used for data cleaning and analysis and drawing of tables and graphs.

\section{RESULTS}

A total of 2,186 Syrian families were interviewed face to face, and information about 2,827 children was obtained. The average age of the children was $1.78 \pm 1.47$ years; 1,570 (55.5\%) were boys, and 1,257 (44.5\%) were girls. The difference between the numbers of boys and girls according to age groups was not statistically significant $\left(\mathrm{p}=0.58, \chi^{2}=2.89\right)$. The distribution by sex and age is depicted in Table 2 . A total of $79 \%$ of the Syrian families $(n=1,726)$ have health insurance from the state, as they are officially registered as "persons under temporary protection" in our country; $20 \%$ of the Syrian families did not have health insurance because they had no official registration; and $1 \%$ of the families had private health insurance.

Less than one-third of the Syrians under temporary protection $(n=664 ; 30.4 \%)$ are registered with a family physician or other health centre. The rate of Syrians unregistered in any health unit was $67.6 \%(n=1,477)$, and the rate of Syrians not answering the question, or not knowing if they were registered, was $2.1 \%$ $(\mathrm{n}=45)$. In the past 6 months, Syrians under temporary protection have visited health institutions or physicians 4,920 times regarding their children. On average, each child had 2.3 health visits.

Of the 2,186 Syrians, with 2,827 children, who answered the question "Has your child ever been vaccinated?", 634 (22.4\%) had never been vaccinated, while 2,193 (77.6\%) had received at least one vaccination. Those who had never had their children vaccinated constituted about one-quarter $(24.7 \%)$ of all the families researched.

Of 2,827 children, the percentage of children who have never received vaccines were as follows: hepatitis $\mathrm{B}$ vaccine $54.7 \%$ $(\mathrm{n}=1,547)$; BCG $62.5 \%(\mathrm{n}=1,768)$; five-component combined vaccine $64.6 \%(\mathrm{n}=1,826)$; CPV 58\% $(\mathrm{n}=1,641)$; OPV $70.8 \%$ $(\mathrm{n}=2,001)$; MMR vaccine $76.6 \%(\mathrm{n}=2,166)$; varicella vaccine $66.8 \%(n=1,889)$; and hepatitis A vaccine 76.0\% $(n=2,148)$. Based on the vaccination schedule, the percentage of children with the appropriate immunization doses were as follows: hepatitis B $26.5 \%(\mathrm{n}=750)$; BCG $36.1 \%(\mathrm{n}=1,020)$; five-component combined vaccine $25.5 \%(n=722)$; CPV $24 \%(n=685)$; OPV $11.3 \%$ $(\mathrm{n}=320)$; MMR 3.8\% $(\mathrm{n}=107)$; varicella $21.1 \%(\mathrm{n}=596)$; and hepatitis A 5.4\% $(n=154)$ (Table 3).

When asked the question "Which vaccinations should be given to children under 5 years of age", $68.8 \%(n=1,503)$ of all participants did not have any knowledge about which vaccinations should be administered to these children. The vaccine considered most important is the polio vaccine, but only $16.3 \%(n=356)$ of all Syrians under temporary protection said it was necessary. $90.5 \%$ $(n=1,985)$ of children were taken for their most recent vaccination by their mothers, while $7.7 \%(\mathrm{n}=167)$ were taken by their fathers, and $1.8 \%(n=39)$ by others (sister, brother, one of their elders, etc.) (Fig. 1). The decision to vaccinate was made by the mother $52.4 \%(n=1,149)$ of the time, by the father $13.3 \%(n=292)$ of the time, and by both parents $33.5 \%(n=735)$ of the time. The

Table 2. Gender distribution by age group $(N=2,827)$

\begin{tabular}{|l|c|c|c|c|c|c|}
\hline \multirow{2}{*}{ Age (years) } & \multicolumn{2}{|c|}{ Boys } & \multicolumn{2}{|c|}{ Girls } & \multicolumn{2}{c|}{ Total } \\
\cline { 2 - 7 } & $\mathbf{n}$ & $\%$ & $\mathbf{n}$ & $\%$ & \multicolumn{2}{c|}{$\mathbf{n}$} \\
\hline 0 & 424 & 54.3 & 357 & 45.7 & 781 & 100.0 \\
\hline 1 & 272 & 53.3 & 238 & 46.7 & 510 & 100.0 \\
\hline 2 & 325 & 57.5 & 240 & 42.5 & 565 & 100.0 \\
\hline 3 & 226 & 55.9 & 178 & 44.1 & 404 & 100.0 \\
\hline 4 & 323 & 57.0 & 244 & 43.0 & 567 & 100.0 \\
\hline Total & 1,570 & 55.5 & 1,257 & 44.5 & 2,827 & 100.0 \\
\hline
\end{tabular}

Table 3. Percentage vaccinated according to the vaccination schedule $(N=2,827)$

\begin{tabular}{|c|c|c|c|c|c|c|c|c|c|}
\hline \multirow{2}{*}{ Vaccination } & \multirow{2}{*}{$\begin{array}{l}\text { Required } \\
\text { doses } \\
(n)^{*}\end{array}$} & \multicolumn{2}{|c|}{ Not vaccinated } & \multicolumn{2}{|c|}{$\begin{array}{c}\text { Completed vaccine } \\
\text { doses }\end{array}$} & \multicolumn{2}{|c|}{$\begin{array}{c}\text { Incomplete vaccine } \\
\text { doses }\end{array}$} & \multicolumn{2}{|c|}{$\begin{array}{c}\text { Number of doses } \\
\text { not yet due }\end{array}$} \\
\hline & & $\mathrm{n}$ & $\%$ & $\mathrm{n}$ & $\%$ & $\mathrm{n}$ & $\%$ & $\mathrm{n}$ & $\%$ \\
\hline Hepatitis B & 3 & 1,547 & 54.7 & 750 & 26.5 & 463 & 16.4 & 67 & 2.4 \\
\hline BCG & 1 & 1,768 & 62.5 & 1,020 & 36.1 & 0 & 0.0 & 39 & 1.4 \\
\hline Five-component combined & 3 & 1,826 & 64.6 & 722 & 25.5 & 258 & 9.1 & 21 & 0.7 \\
\hline CPV & 3 & 1,641 & 58.0 & 685 & 24.2 & 174 & 6.2 & 327 & 11.6 \\
\hline OPV & 2 & 2,001 & 70.8 & 320 & 11.3 & 395 & 14.0 & 111 & 3.9 \\
\hline MMR & 1 & 2,166 & 76.6 & 107 & 3.8 & 0 & 0.0 & 554 & 19.6 \\
\hline Varicella & 1 & 1,889 & 66.8 & 596 & 21.1 & 0 & 0.0 & 342 & 12.1 \\
\hline Hepatitis A & 2 & 2,148 & 76.0 & 154 & 5.4 & 33 & 1.2 & 492 & 17.4 \\
\hline
\end{tabular}

*The number of doses required is for the 0-4-year age range according to the Republic of Turkey, Ministry of Health's Childhood Vaccine Schedule. Dose numbers do not include doses administered after $0-4$ years of age and booster doses. 
decision to vaccinate was rarely, $0.8 \%(n=17)$, made by others such as elders (grandmother, grandfather) (Fig. 2).

\section{DISCUSSION}

While $74 \%$ of the Syrian children participating in our study were born in Turkey, $20 \%$ were born in Syria. Only 24\% of children 4 years of age were born in Turkey, while all children under 2 years of age were born in Turkey.

Of the $22.4 \%(n=634)$ of children who had never been vaccinated, 425 (67.0\%) were born in Turkey. In other words, 1 in 5 Syrian children born in Turkey $(20.3 \%)$ had never been vaccinated. It is quite concerning that the proportion of Syrian children who were born in Turkey but have never been vaccinated is so high. The percentage of Syrian children under temporary protection who have never received vaccines are as follows: hepatitis B vaccine 54.7\%; BCG 62.5\%; five-component combined vaccine 64.6\%; CPV 58.0\%; OPV 70.8\%; MMR 76.6\%; varicella vaccine $66.8 \%$; and hepatitis A vaccine $76.0 \%$. The fact that the percentage of children who have never been vaccinated exceeds $60 \%$, except for hepatitis $\mathrm{B}$ vaccine and $\mathrm{CPV}$, is of particular concern.

Based on the vaccination schedule, the percentage of children who have been appropriately immunized are as follows: hepatitis B 26.5\%; BCG 36.1\%; five-component combined vaccine 25.5\%; CPV 24.2\%; OPV 11.3\%; MMR 3.8\%; varicella 21\%; and hepatitis A $5.4 \%$.

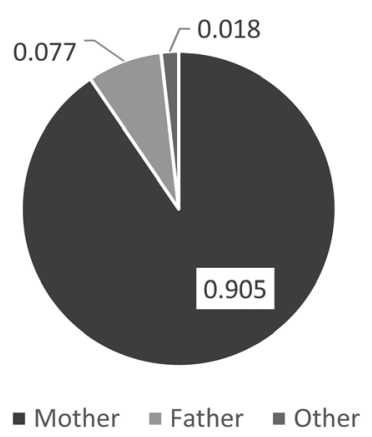

Fig. 1. Who took the child to the last vaccination.

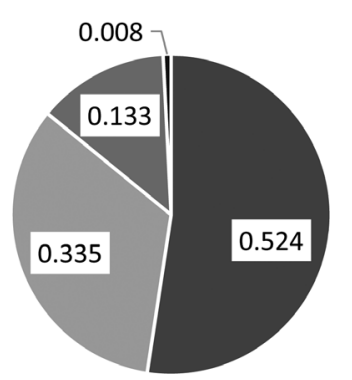

- Mother Mother-Father Together - Father - Family Elders

Fig. 2. Who made the decision to vaccinate.
Based on the 2013 report of Syrian refugees in Turkey, while $26.2 \%$ of in-camp Syrians under the age of 5 years have not received the OPV vaccine, this ratio increases to $45.4 \%$ for those living outside the camps. When we examine the children under the age of 10 years, $28.2 \%$ of those who live in camps have not received the measles vaccine, and $41.3 \%$ of those living outside the camps have not received it (6).

In a study investigating 12-23-month-old Syrian refugee children, the rate of fully vaccinated children was found to be $24.5 \%$ in Jordan and $12.5 \%$ in Lebanon (7). In another study in Lebanon in $2014,78 \%$ of children aged $9-59$ months had received at least one dose of measles vaccine (8). In the 2015 Lebanese study, half of the children aged $0-59$ months were administered pentavalent vaccine (diphtheria, tetanus, pertussis, hepatitis B, Haemophilus influenzae type B), and 53\% were vaccinated for MMR (9). Of the Syrian refugee children aged 9-59 months living in Jordan, 87\% in 2014 and $82 \%$ in 2015 were vaccinated against measles (10).

In order to increase the vaccination rate among Syrian children, the target audience should be mothers as they are responsible for taking children for their vaccination $90 \%$ of the time. Syrian families likely did not have enough knowledge about immunization, as only $60 \%$ of families stated that their child had a card documenting their vaccinations.

Approximately $70 \%$ of Syrians do not know which vaccinations should be administered to children under the age of 5 years. This low level of knowledge about vaccination, and the fact that it has remained low despite residing under Turkish protection for considerable amount of time, is an indication of communication difficulties with the Syrian refugees. Because the refugees were primarily from rural areas and small towns within Syria, it may not be surprising that their knowledge about vaccination is incomplete and inadequate. However, given the length of their stay in Turkey, the fact that this important information has not been transmitted to them highlights the need for a significant educational programme to address this problem.

\section{CONCLUSION}

Children aged 0-59 months are susceptible to the diseases for which routine immunization is provided. Children of Syrian refugees are particularly susceptible, as primary care services have a low priority in their current environment and they may have been exposed prior to their immigration. It is imperative to improve the vaccination rate among these children as well as provide their parents with better information regarding the need for vaccination.

\section{Acknowledgements}

The project received grant from the World Health Organization's Turkey Office.

\section{Conflict of Interests}

None declared

\section{REFERENCES}

1. UN Refugee Agency. Global trends: forced displacement in 2015. Geneva: UNHCR; 2016. 
2. UN Refugee Agency. Syria regional refugee response [Internet]. UNHCR; 2019 [cited 23 March 2019]. Available from: https://data2.unhcr.org/en/ situations/syria/location/113.

3. Akbaba M, Demirhindi H, editors. Basic public health. Ankara: Academician Publications; 2017. (In Turkish.)

4. Disaster and Emergency Management Authority. Population influx from Syria to Turkey [Internet]. Ankara: AFAD Publications; 2014 [cited 11 Nov 2019]. Available from: https:/www.afad.gov.tr/kurumlar/afad.gov. tr/17933/xfiles/population_influx_1_.pdf

5. Topaç $\mathrm{O}$. Vaccination applications in our country extended immunization program. In: 6. PUADER Congress; 2017 Oct 23-25; Antalya, Turkey.

6. Disaster and Emergency Management Authority. Syrian refugees in Turkey, 2013: field survey results [Internet]. Ankara: AFAD Publications; 2013 [cited 11 Nov 2019]. Available from: https://www.afad.gov. tr/kurumlar/afad.gov.tr/17949/xfiles/syrian-refugees-in-turkey-2013 print 12 11_2013 eng 1_.pdf

7. Roberton T, Weiss W, Doocy S; Jordan Health Access Study Team; Lebanon Health Access Study Team. Challenges in estimating vaccine coverage in refugee and displaced populations: results from household surveys in Jordan and Lebanon. Vaccines (Basel). 2017;5(3):22. doi: $10.3390 /$ vaccines 5030022 .
8. United Nations High Commisioner for Refugees. Health Access and Utilization Survey among Non-Camp Refugees in Lebanon; UNHCR: Geneva, Switzerland, 2014.

9. United Nations High Commissioner for Refugees; The United Nations Children's Fund; World Food Programme. Vulnerability assessment of Syrian refugees in Lebanon: 2015 report [Internet]. Geneva: UNHCR; 2015 [cited 11 Nov 2019]. Available from: https://data2.unhcr.org/en/ documents/download/44416.

10. United Nations High Commissioner for Refugees. At a glance: health access and utilization survey among non-camp refugees in Jordan [Internet]. Geneva: UNHCR; 2015 [cited 11 Nov 2019]. Available from: https:// reliefweb.int/sites/reliefweb.int/files/resources/JordanHAUS2015FINALReport-2.pdf.

Received September 16, 2018 Accepted in revised form November 11, 2019 